\title{
Integral Pattern of Bench Stability on all Adjacent Rock Of Open-Pit Mine in Solid Rocks
}

\author{
Nikolay A. Godovnikov ${ }^{1}$, Aleksander V. Konovalov ${ }^{2}$, Vladimir A. Dunaev ${ }^{3}$, Ignat M. Ignatenko ${ }^{4}$ \\ 1, 2 open joint-stock company VIOGEM, 308007, Belgorod, Bogdan Khmelnytsky Av., 86 \\ ${ }^{3,4}$ Belgorod State University,308015, Belgorod, Pobedy str., 85, \\ *Email: ${ }^{1}$ godovnikov_na@geomix.ru, ignatenko_i@bsu.edu.ru
}

Received: 21st October 2017 Accepted: 16th November 2017, Published: 31st December 2017

\begin{abstract}
The article presents the integrated image of bench stability across the entire adjacent pit area on the basis of a probabilistic method to predict the azimuthangular parameters of cracks that limit the potential prisms of the pit bench collapse that are put in the final position, as well as those planned to be set to the limiting contour in the form of a software component as the part of the specialized geoinformation GIS system "Stability".

The computer technology for the probabilistic prediction of the most frequently encountered types of the quarry pit deformation is developed: a wedge and a flat one. The efficiency of this technology is proved by the example of the Kovdorsky MPP (Russia, Murmansk region) by the means of the comparative analysis concerning the actual and probabilistic location of these types of deformations, which showed the confinement of bench deformations to the sections of the quarry, limited by the isolines of such deformations occurrence probability within $80-100 \%$. This technology is applicable to any quarries in rock massifs.
\end{abstract}

Keywords: Rock Massif, Open Pit, Berm, Stability, Geoinformation System, Computer Technology, Imitating Modeling, Probabilistic Forecast.

\section{Introduction}

The main cause of quarry bench deformations in rock massifs are differently oriented fracture disruptions (cracks), which form potential prisms of collapse by themselves or in combination with each other at certain spatial relationships with the slopes and the berms of ledges. A prompt and a reliable prediction of potential collapse prisms is the basis for a safe conduct of opencast mining.

The forecast of quarry ledge deformations consists in the obtaining of an integral picture of ledge stability along the adjacent pit area of the quarry in the form of isolines for the probability of deformation manifestation. The development of sets for potential collapse prisms to develop the contours along them is carried out by the probabilistic method of forecasting in respect of their azimuthal-angular parameters $[1,2]$ realized as a software component of PF Stability as the part of the specialized geoinformation system GIS Stability [3, 4], developed on the basis of mining and geological GIS GEOMIX [5] and inheriting its functional possibilities. This computer technology is based on the following algorithm (Fig. 1).

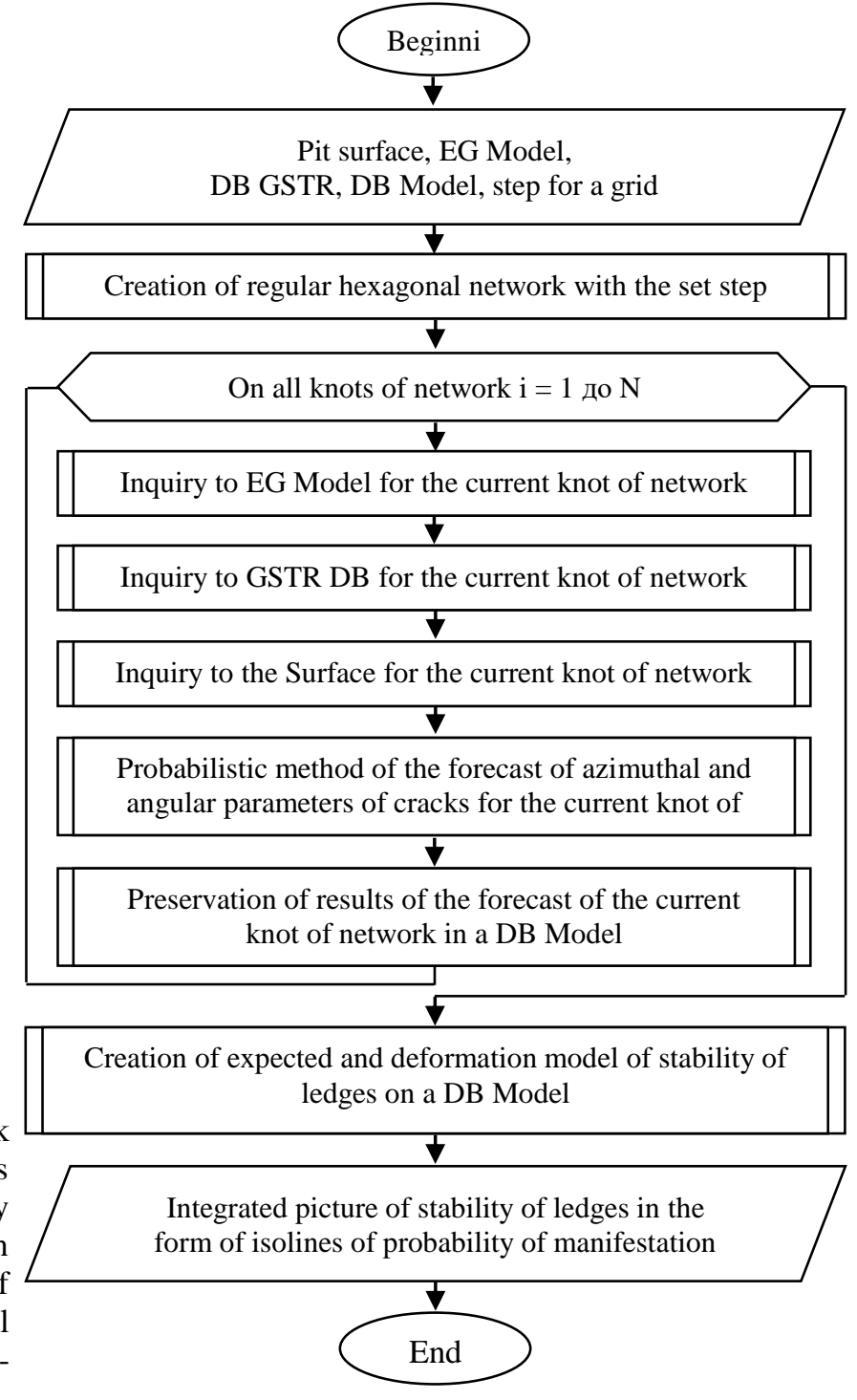

Figure 1: Flowchart of an Algorithm of the Forecast of Deformations of Ledges for Pit Perimeter: EG Model - Engineering-Geological Model; GSTR DB - The Database of Geological and Structural Information; DB Model - The Database of Results of Simulation and the Forecast of Deformations of Ledges 


\section{Study Methods}

The specialized GIS Stability has the developed computer technology for probabilistic forecasting of two most common types of deformations: wedge and flat one. A wedge collapse is caused by the combination of two diagonal cracks falling towards each other, the line of crossing of which covers a ledge berm. A flat type of collapse is manifested much less often than the wedge one, but more dangerous, and this is related to longitudinal cracks falling to the quarry than the slope of the ledge. Based on the technique described below, the creation of computer technologies for any type of deformation is a purely technical task.

The initial data for the implementation of this algorithm: $3 \mathrm{~d}$ model of the pit surface, BD GSTR, IG model (stores the information about the physical and mechanical characteristics of the deposit rocks and ores), the step of a regular hexagonal network creation for a geometric query to the database of geological and structural information.

First, a regular hexagonal grid is created along the entire perimeter of the quarry to carry out geometric queries on the necessary information. Then, the queries are made to the database of crack occurrence elements for each node of the grid, IG of the deposit model and the surveyor surface of the quarry.

After that, the procedure of probabilistic forecast for azimuth-angular parameters of cracks in respect of each grid node is started. First, a circular diagram of the orientation of cracks in the given section of the quarry is developed. Then, by the means of simulation modeling [6], a range of values for the elements of crack occurrence is established in which potential prisms of ledge collapse are formed: for wedges $(\alpha-$ angle between the azimuths of the cracks bounding the prism, $\beta$ - the angle of their incidence), for flat ones ( $\beta$ - the incidence angle of cracks). In the process of potential collapse prism selection the probability of a pole occurrence is estimated on a circular diagram for each crack participating in the formation.

In this case, the circular diagram is used as the histogram of a random function of two variables $F(\alpha$, $\beta$ ), where $\alpha$ and $\beta$ are the azimuth and the angle of the crack incidence respectively. Then the probability of a potential collision prism of one or another type is dtermined at a given section of the quarry. Since the position and the elements of crack occurrence forming such prisms are independent of each other, this probability $(\mathrm{P})$ will be equal to the product $(\Pi)$ of the probabilities (p) for each such crack:

\section{$\mathrm{P}=\prod_{\mathrm{i}=1}^{\mathrm{N}} \mathrm{p}_{\mathrm{i}}$,}

where $p_{i}$ is the probability of $i$-crack occurrence; $\mathrm{N}$ is the number of cracks that limit the potential collapse prism (flat - 1, wedge - 2).

The final operation is the estimation of the most probable azimuth values and the incidence angle of cracks that limit the potential prisms of ledge collapse in a given section of the quarry. To do this, it is necessary to select those from the total set of prisms whose probability of realization is the maximum one. Depending on the type of deformation, all potential collapse prisms are grouped according to one of the indicators, similar to the way it was done in simulation modeling [4], namely, according to the angle between the azimuths of crack extension, and then according to the incidence angle of cracks forming the wedge-type collapse prism, or by the angle of incidence for a flat type of collapse. Then, for all groups, we find the sum of probabilities for each collapse prism that makes the part of a group. Thus, we estimate the probabilities by groups in which at least one collapse can occur. Then we select the prisms for which the probability value of their realization is greatest one.

Further we solve the inverse problem, i.e. according to the established maximum probability of a collapse prism realization, we determine the azimuth-angular parameters of the cracks forming it:

$\left\{\left(\alpha_{\mathrm{i}}, \beta_{\mathrm{i}}\right)\right\}=\mathrm{P}$, where $\mathrm{i}=1 . . \mathrm{N}, \mathrm{N}$ is the number of cracks forming the prism, $\mathrm{P}$ is the probability of a potential collapse prism, $\left(\alpha_{\mathrm{i}}, \beta_{\mathrm{i}}\right)$ - the azimuthal-angular parameters of the i-th crack of a potential collapse prism.

Thus, we obtain the most probable azimuthal-angular parameters of the cracks that form potential collision prisms of these types at a given section of a quarry. At each step of iteration, the results of the azimuthangular crack parameter forecast are stored in the DB Model.

Thus, we obtain the most probable azimuthal-angular parameters of the cracks that form potential collision prisms of these types at a given section of the quarry. At each step of the iteration, the results of crack azimuth-angular parameter forecast are stored in the DB Model.

Based on the prognostic-deformation model of the wedge and flat type of collapses, an integral picture of the pit ledge stability is developed in the form of isolines concerning these deformations manifestation probability.

\section{Results and Discussion}

The basic object of research is the quarry of the "Zhelezny" mine by Kovdorsky MPP (Russia, Murmansk region), which has been developing Kovdorsky apatite-magnetite deposit since 1962 in a rock massif, in which the most frequently encountered types of ledge deformation (wedge, flat ones) are manifested most clearly. In order to assess the efficiency of the proposed method, the comparison is performed between the positions of deformation sections for the quarry ledges with the established ones by this method.

Based on the results of a probabilistic prediction concerning the deformations of the wedge and flat types, the maps were plotted in the isolines of their manifestation probability with the provision of deformation positions for them (Fig. 2). 
a)

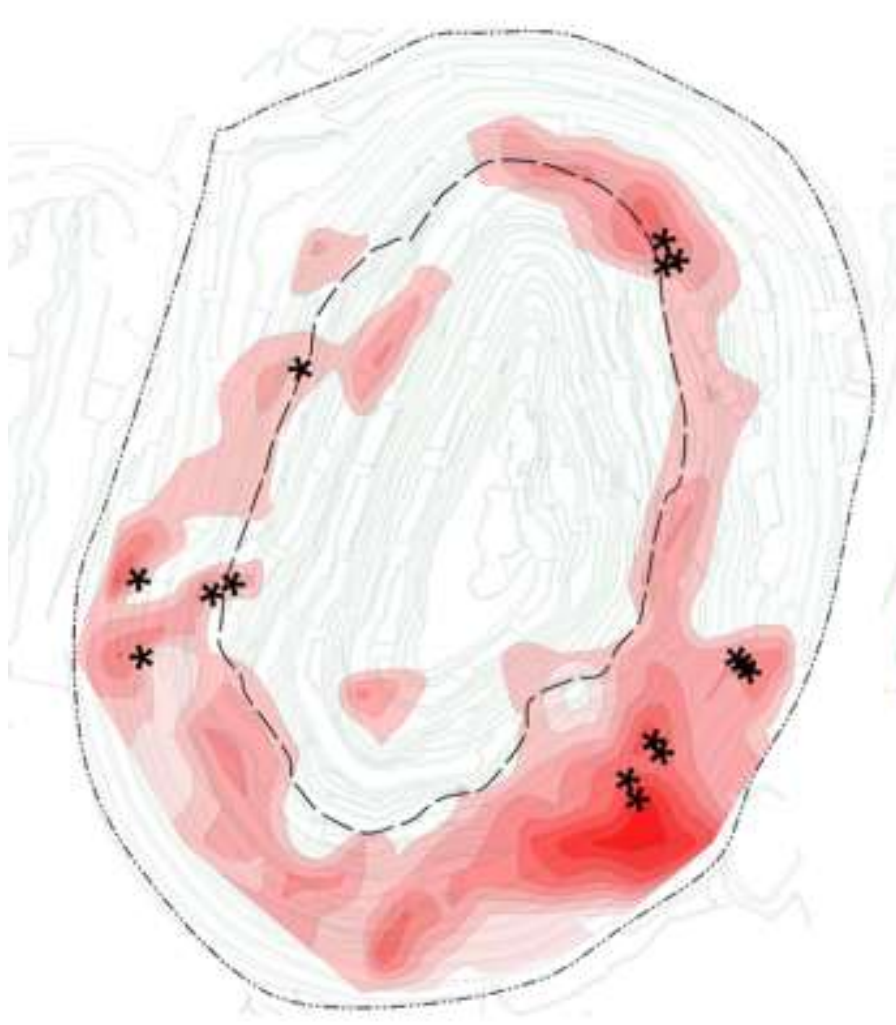

б)

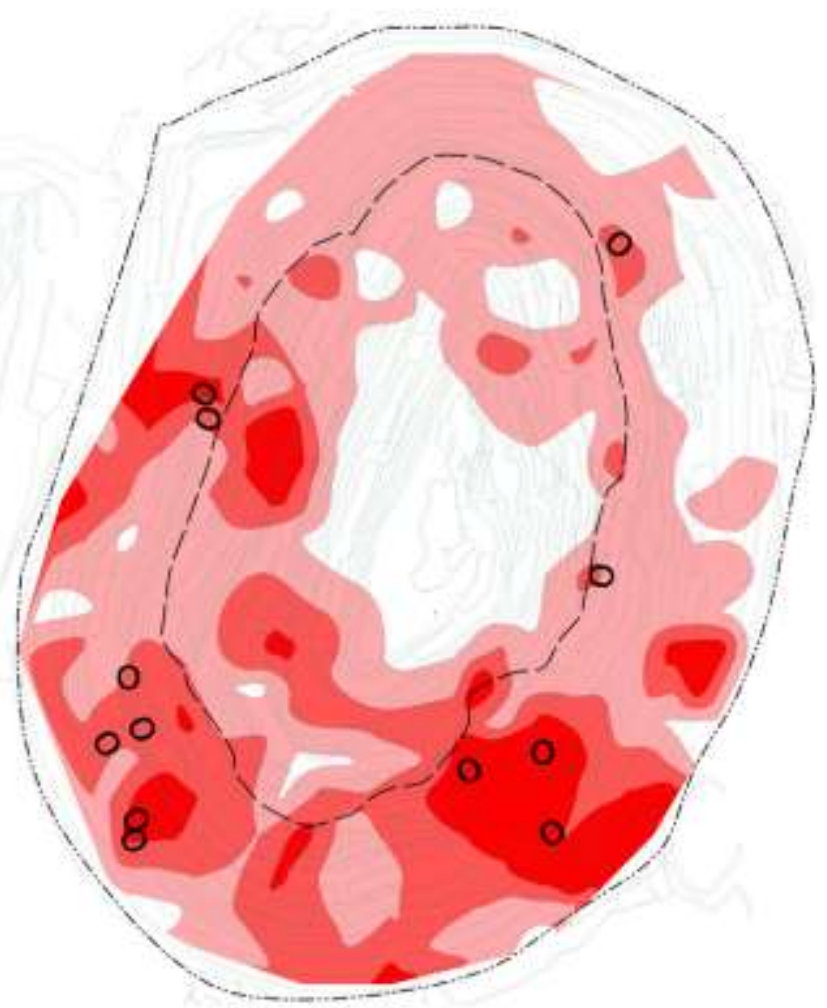

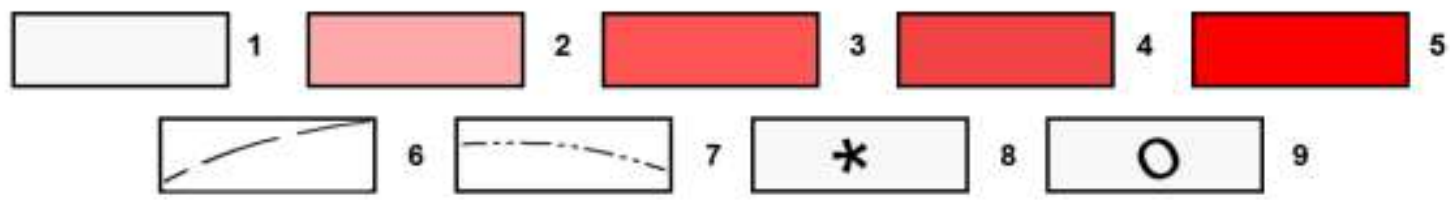

Fig. 2: Forecast-Deformation Model of the Open Pit Mine "Iron" and the Position of the Deformed Deformations of the Ledges: a) Wedge, b) Flat. 1-5 - Probability of Deformation Realization, \%: 1- to 20, 2from 20 to 40, 3- from 40 to 60, 4- from 60 to 80, 5- from 80 to 100; 6- Boundary of the Working Area; 7Boundary of the Quarry; 8 - Completed Wedge Deformations; 9 - Flat Deformations

\section{Summary}

The comparative analysis of the actual and the probabilistic location of these types of deformations shows their good convergence. The deformations of ledges are confined to the areas limited by the isolines of deformation realization probability which make 80$100 \%$. The abovementioned indicates the expediency of the proposed method use for the prediction of pit ledge potential deformations in rock massifs.

\section{Conclusions}

1. The authors of the article have developed and tested the technique and the computer technology of probabilistic forecasting concerning the position of potential deformations of ledges in rock massifs on the current quarry.

2. The positive results of such approbation make it possible to recommend the use of this technology at any quarries in rock massifs.

\section{References}

[1] Dunaev V.A., Godovnikov N.A. Estimation and prognosis of quarry ledge stability in rock massifs on the basis of geoinformation technologies. - Mining information analytical bulletin-2014. - № 4. - pp. 134137.

[2] Godovnikov A.N., Dunaev V.A. Probabilistic method for the prediction of pit ledge potential deformations in rock massifs. - Mining information analytic. bull. - 2015. - №5. - pp. 81-83.

[3] Certificate of state registration for the computer program № 2014619048 "Specialized geoinformation system Stability" (GIS Stability). 8.09.2014.

[4] Certificate of the database state registration №2014621557. The database of the specialized geoinformation system Stability. 18.11.2014.

[5] State registration certificate of the computer program №2004612469 "Mining and geological information system GEOMIX" (GIS GEOMIX). 9.11.2004. 
[6] Godovnikov N.A., Dunaev V.A. Simulation modeling of pit ledge collapse prisms. - Scientific bulletins of the BelSU, series "Natural Sciences", 2014, No. 17 (188), issue 28, pp. 148-153.

[7] Whitman RV (1984). Evaluating and calculated risk in geotechnical engineering: 7th Terzaghi Lecture. Journal of Geotechnical Engineering 110 (2), 145-188.

[8] Priest SD \& Brown ET (1983). Probabilistic stability analysis of variable rock slopes. Transactions of Institution of Mining and Metallurgy, Section A: Mining Industry 92, A1-12.

[9] Kirsten HAD (1983). Significance of the probability of ailure in slope engineering. The Civil Engineer in South Africa 25(1).

[10] Swan G \& Sepulveda R (2000). Slope stability at Collahausi. In Slope Stability in Surface Mining (eds WA Hustrulid, KM McCarter \& DJA Van Zyl), pp. 163-170. SME, Colorado.

[11] Sullivan TD (2006). Pit slope design and risk - a view of the current state of the art. In Proceedings of International Symposium on Stability of Rock Slopes in Open Pit Mining and Civil Engineering, Cape Town. South African Institute of Mining and Metallurgy, Johannesburg. 